\title{
O CONCEITO DE ALIENAÇÃO E O PROCESSO DE REPRODUÇÃO DA SOCIEDADE NA EDUCAÇÃO
}

\author{
EL CONCEPTO DE ALIENACIÓN Y EL PROCESO DE REPRODUCCIÓN DE LA \\ SOCIEDAD EN LA EDUCACIÓN
}

\section{THE ALIENATION CONCEPT AND THE SOCIAL REPRODUCTION PROCESS IN EDUCATION}

DOI: http://dx.doi.org/10.9771/gmed.v12i3.37078

\begin{abstract}
Aline de Carvalho Moura ${ }^{1}$
Resumo: A partir de uma discussão sobre o conceito de alienação, este artigo tem como objetivo problematizar a relação que se estabelece entre a sociedade e a educação, pensando a forma como os processos educacionais reproduzem as estruturas da sociedade capitalista. Metodologicamente, apresentamos uma epistemologia marxista acerca da problemática da alienação sob a perspectiva materialista histórica de orientação ontológica argumentando, como esse conceito pode explicar a relação entre educação e sociedade. Como considerações, questionamos uma reformulação significativa da educação sem uma correspondente transformação do quadro sócio-político-econômico no qual as práticas educativas devem cumprir suas funções.

Palavras-chave: Alienação. Sociedade Capitalista. Reprodução. Educação. Marx.
\end{abstract}

Resumen: Basado en una discusión sobre el concepto de alienación, este artículo tiene como objetivo problematizar la relación establecida entre sociedad y educación, pensando en la forma en que los procesos educativos reproducen las estructuras de la sociedad capitalista. Metodológicamente, nos basamos en una epsitemología marxista sobre el problema de la alienación desde la perspectiva materialista histórica de orientación ontológico, argumentando cómo este concepto explique la relación entre educación y sociedad. Como consideraciones, cuestionamos una reformulación significativa de la educación sin una transformación correspondiente del marco sociopolíticoeconómico en que las prácticas educativas deben cumplir sus funciones.

Palabras clave: Alienación. Sociedad capitalista. Reproducción. Educación. Marx.

Abstract: Based on a discussion on the concept of alienation, this article aims to problematize the relationship established between society and education, thinking about the way in which educational processes reproduce the structures of capitalist society. Methodologically, we present a marxist-based epistemology about the problem of alienation from the historical materialist perspective of ontological orientation, arguing, how this concept can explain the relationship between education and society. As considerations, we question a significant reformulation of education without a corresponding transformation of the socio-political-economic framework in which educational practices must fulfill their functions.

Keywords: Alienation. Capitalist society. Reproduction. Education. Marx.

\section{Apontamentos iniciais sobre o conceito de alienação}

O conceito de alienação é histórico, tendo uma aplicação analítica em uma ligação entre sujeito, objeto e condições concretas específicas. É também, um conceito vasto que pode englobar várias maneiras e formas de pensamento. Entretanto, o conceito de alienação exposto, neste trabalho, não se apresenta com um interesse em si mesmo, mas como aporte de um estudo que prioriza a compreensão deste 
conceito no que diz respeito à forma como a educação e suas instituições reproduzem alguns pressupostos da sociedade capitalista.

Este artigo se estrutura a partir da perspectiva que considera um equívoco negar a relação íntima e profunda que existe entre os processos educacionais e os processos sociais mais abrangentes de reprodução da ordem do capital. Nesse sentido, o objetivo deste artigo é problematizar a discussão sobre a relação que se estabelece entre a sociedade e a educação, pensando a forma como os processos educacionais reproduzem as estruturas da sociedade capitalista, a partir do conceito de alienação.

Metodologicamente, apresentamos uma epistemologia de base marxista acerca da problemática da alienação sob a perspectiva materialista histórica de orientação ontológica, argumentando, como esse conceito pode explicar a relação entre educação e sociedade. O caminho empreendido, neste artigo, trata de uma pesquisa bibliográfica que parte das discussões sobre o conceito de alienação e a forma como os desdobramentos deste conceito podem traduzir os mecanismos próprios do sistema educacional na sociedade regida pelo poder do capital.

Segundo István Mészáros (2006), a alienação é um conceito eminentemente histórico. Se o homem é alienado, isso se concretiza em uma situação de relação, pois o homem, como sujeito dessa alienação, manifesta-se sempre em um contexto histórico. Por isso, entendemos, a partir da discussão de Mészáros (2006) que, por sua superioridade sobre os intelectuais que o precederam, Marx é a base para a compreensão desse conceito. Sua história política e teórica, além de suas condições como agente dessa história, aconteceu no seio dos acontecimentos econômico-sócio-políticos de sua época.

Antes de discutir, mais especificamente a relação entre educação e sociedade, é importante trazer alguns apontamentos sobre o conceito de alienação, a fim de que possamos tecer as relações que se estabelecem entre os processos educacionais e os processos sócio-político-econômicos mais abrangentes.

$\mathrm{Na}$ perspectiva teórica deste artigo, compreendemos que existem algumas questões que giram em torno de um suposto amadurecimento teórico ou algumas rupturas entre os estudos de Marx ao longo de sua trajetória teórica, por isso, é importante deixar claro o ponto de onde partiram nossas inquietações e a perspectiva que abordamos dentro do campo do Marxismo.

Para realizar estudos sob a perspectiva do Marxismo, torna-se necessário compreender que:

O Marxismo não é uma filosofia de gabinete que pode ser praticada independentemente das condições predominantes no movimento socialista internacional. Ao contrário, é uma visão de mundo que, desde o início, rejeitou conscientemente a idéia de uma mera interpretação do mundo e se comprometeu com a luta árdua para modificá-lo: tarefa cuja realização é inconcebível sem a implementação bem-sucedida de estratégias políticas adequadas (MÉSZÁROS, 2004, p. 110, grifos do autor).

O campo do Marxismo nos permite pensar a possibilidade de uma sociedade que tenha como parâmetro o ser humano, através de uma visão que trabalhe a lógica desumanizadora e perversa do capital, pensando ainda a possibilidade de uma educação um pouco mais crítica. Entendemos que, ao realizar um estudo sobre a educação e a sociedade fundamentado no conceito de alienação, é importante considerar a história, o homem concreto, que vive, relaciona-se e produz em uma sociedade historicamente determinada. Dentro desse pressuposto, apresentaremos o que entendemos como um aprofundamento 
teórico na trajetória intelectual de Marx, pensando a presença do conceito de alienação neste processo de revolução teórica por que passou, buscando explicitar o terreno de onde partimos para realizar as articulações entre a educação, a sociedade e o conceito de alienação.

\section{O conceito de alienação na trajetória intelectual de Marx}

No intuito de fazer alguns apontamentos sobre o conceito de alienação, foi preciso abordar alguns pontos existentes ao longo do aprofundamento teórico vivido por Karl Marx. Marx, ao tratar desse conceito, difere de suas principais influências no campo da filosofia, tanto de Georg Wilhelm Friedrich Hegel, quanto de Ludwig Feuerbach, pois ultrapassou tanto a abstração hegeliana quanto o retrocesso feuerbachiano na historicidade.

A partir do momento em que se deparou com as contradições dos sistemas sociais existentes, Marx passou a pensar o conceito de alienação sem a acepção positivista compreendida até então. Essa acepção positivista sustentava uma visão abstrata do conceito de alienação, pois negligenciava, ou até mesmo descartava, a historicidade do processo de aproximação com o real.

Analisando parte da trajetória da atividade intelectual e o terreno de onde partiam suas principais reflexões e questionamentos acerca da sociedade, identificamos uma revolução teórica no pensamento de Marx, na medida em que se desprendeu do intelectualismo burguês e da problemática hegeliana, devido às contradições e limitações encontradas no sistema conceitual elaborado por Hegel, uma vez que esse sistema assumia posições cada vez mais abstratas e extremistas, distanciando-se da luta política.

Posteriormente, Marx afastou-se, também, da teoria feuerbachiana, após a constatação de suas limitações, já que concebia o homem de forma muito genérica, além de perceber que, mesmo partindo de uma filosofia voltada para o homem concreto, essa era uma concepção naturalista e a-histórica.

Pensando a revolução teórica de Marx, sua aproximação, cada vez maior, com o proletariado, seu afastamento da concepção antropológica de Feuerbach e a elaboração da teoria científica do marxismo, torna-se necessário fazer alguns apontamentos sobre sua passagem pelo círculo do hegelianos e pela teoria de Feuerbach, para que possamos compreender como o conceito de alienação passou por essa revolução teórica, ganhando as características assumidas no materialismo histórico de Marx.

Para Hegel (1999), a história da humanidade seria a própria história da alienação do homem. Ainda para esse filósofo, a alienação é o processo pelo qual o mundo parece constituído de coisas independentes umas das outras, sendo indiferente à consciência. Dentro dessa visão minimalista de Hegel sobre a alienação, podemos identificar a alienação na sociedade, que seria, dentro dessa análise, "a alienação individual dos seres humanos que perseguem seus próprios desejos na separação dos verdadeiros trabalhos institucionais de sua sociedade, onde são controlados pela astúcia da razão" (FORNES, 2008, p. 30). Configura-se, nessa ideia, o homem como alienado do sistema social, uma vez que não sabe que seus desejos são determinados pelo sistema, assim como também o determinam.

O engajamento de Marx no círculo dos jovens hegelianos contribuiu para seu posicionamento filosófico. Entretanto, "seguindo os passos de Bruno Bauer, quando da sua opção pelo ateísmo, os jovens 
hegelianos, agora a esquerda hegeliana, passam a distanciar-se das posições de Hegel, lutando contra a religião, na defesa da filosofia” (HANDFAS, 2006, p. 23). Por conta das controvérsias, Marx passou a identificar as limitações no sistema conceitual elaborado por Hegel, indicando a presença de posições abstratas e extremistas, já que se distanciavam das questões sociais e políticas. Marx apresentou sua oposição ao caráter vazio e sem conteúdo científico dos jovens hegelianos em uma carta a Ruge, de 1842

Convidei-os a não se contentarem com raciocínios vagos, com frases pomposas, a não se mostrarem excessivamente complacentes para com suas próprias pessoas, a preocuparem-se com a análise exacta das situações concretas e a darem provas de conhecimentos rigorosos (MARX apud HANDFAS, 2006, p. 24).

Percebendo as posições abstratas do sistema de Hegel, juntamente com sua posição filosófica, a política tornou-se o fator decisivo para o rompimento de Marx com o hegelianismo. Contudo, Marx não abandonou o conceito de alienação em seus passos políticos e teóricos, e atribuiu novas perspectivas ao conceito, livrando-se do idealismo alemão. Na afirmativa de Leandro Konder (1965), podemos perceber os novos rumos desse conceito:

Com o conceito hegeliano de alienação acontecia, pois, algo parecido ao que se passou com o método dialético utilizado por Hegel: em Hegel, a dialética estava de cabeça para baixo; para poder usá-la, Marx precisou recolocá-la sobre seus próprios pés. Para poder utilizar o conceito de alienação, Marx precisou arrancá-lo aos quadros da filosofia hegeliana, precisou libertá-lo da acepção metafísica que assumira dentro daqueles quadros, decompondo-o, recompondo-o, atribuindo-lhe novos conteúdos e dando-lhes novas dimensões (KONDER, 1965, p. 17).

Após notar o descompasso dentro do hegelianismo, Marx encontrou em Ludwig Feuerbach a possibilidade de elaborar a crítica ao idealismo, a partir do concreto. Na obra $A$ essência do Cristianismo, Feuerbach (2002) ataca o idealismo hegeliano, desmistificando-o e dando um novo conceito para alienação.

A teoria de Feuerbach deve-se à sua crítica a Hegel, cujo principal problema consistia em supor que o pensamento era desprovido de seu conteúdo real. Feuerbach (2002) formulou suas teses materialistas, colocando no centro de seus estudos o homem.

O homem era posto por Feuerbach no centro da natureza, sempre voltando para si, por possuir uma consciência. Seguindo a afirmação de Feuerbach (2002) apresentada acima, a essência só é revelada no próprio objeto transformado pelo homem. Nesse sentido, Feuerbach traz para o concreto, para o real, o que vinha sendo considerado como algo de um ser puro e abstraído de suas determinações. Na sua análise, bastaria substituir, dentro de um mesmo método, o mundo das ideias pelo mundo material. Todavia, a mudança desse objeto, implicariam também mudanças na estrutura do método.

O ser abstrato, Deus, que constituía a fundamentação de Hegel passou a ser substituído, na filosofia de Feuerbach, pelo homem concreto e pelo mundo sensível, sendo esta nova configuração uma alternativa ao processo de alienação. Na crítica de Feuerbach, o homem não teria como realizar sua essência no mundo devido à alienação religiosa. Para realizar a sua essência, o homem precisa de sua consciência a partir do real, superando a condição de ser alienado.

Contudo, as proposições de Feuerbach haviam caído nas mesmas contradições do idealismo de Hegel, já que colocava o homem no centro de sua análise, porém, deixava de analisar as condições 
objetivas de determinação histórica. Entretanto, o humanismo de Feuerbach, que o fez perceber o concreto, exerceu certa influência sobre Marx. Essa influência fez com que Marx passasse de uma posição filosófica idealista, para uma posição filosófica pelo materialismo, mesmo apresentando ainda muitas lacunas e abstrações.

$\mathrm{Na}$ filosofia materialista de Feuerbach, Marx e Engels identificaram a presença da concepção genérica do homem, constatando as limitações desse pensamento. Em La ideologia alemana (1966), podemos encontrar essa crítica:

É certo que Feuerbach traz aos materialistas "puros" a grande vantagem de ver como o homem também é um "objeto sensível"; mas, além do fato de que ele o vê apenas como um "objeto sensível" e não como uma "atividade sensível", ele também permanece dentro dessa teoria, sem conceber os homens dentro do seu engajamento social, sob as condições de vida existentes feito deles o que são, nunca chega, por essa mesma razão, ao homem realmente existente, ao homem ativo, mas para no conceito abstrato de "homem", e apenas consegue reconhecer na sensação "o homem real, individual, corporal"; [...] Na medida em que Feuerbach é materialista, ele não aparece na história, e na medida em que a história é leva em consideração, ele não é materialista. Materialismo e história aparecem completamente divorciados [...] (MARX e ENGELS, 1966, p. 47, tradução nossa).

Com base nos acontecimentos históricos e na opção filosófica e política centrada na crítica radical à filosofia idealista, onde a história era a realização da ideia, Marx passa a entender que os homens produzem a sua existência em condições históricas e sob relações sociais determinadas.

Partindo das críticas às posições filosóficas de Hegel e, posteriormente, aos argumentos da filosofia de Feuerbach, e entendendo a existência humana como uma realidade histórica e produzida sob determinadas relações sociais, Marx engajou-se nas lutas políticas e, em especial, nas lutas políticas do proletariado, aprofundando-se, cada vez mais, na análise materialista da sociedade.

Após breves apontamentos sobre o que apresentamos aqui como uma revolução teórica e intelectual de Marx, percebemos o desenvolvimento do conceito de alienação, também dentro de um processo de revolução teórica, onde assumiu novas configurações e importantes desdobramentos. Segundo Mészáros (2006), na realização concreta da potencialidade do gênio de Marx, sua apreensão do conceito de alienação, a partir da auto-alienação do trabalho, representou o elemento crucial de sua grande síntese.

Mészáros (2006) afirma que foi na obra Manuscritos de 1844 que foram lançados os fundamentos do conceito de alienação no pensamento marxista. Ao analisar o conceito de alienação, Marx indicou seus quatro principais aspectos, que seriam a alienação dos seres humanos em relação à natureza, à sua própria atividade produtiva, à sua espécie, como espécie humana, e em relação aos outros; afirmando que isso não era uma fatalidade da natureza, e sim uma forma de auto-alienação (MARX, 2004). Essa auto-alienação não se caracteriza por uma força externa, natural e despretensiosa, mas aparece como resultado de um tipo determinado de desenvolvimento histórico.

Na obra Manuscritos econômico-filosóficos, Marx (2004) aprofunda a explicação do conceito de alienação, apresentando problemas filosóficos relacionados com a experiência da auto-alienação. De acordo com Mészáros (2006), nos Manuscritos econômico-filosóficos, Marx afirmava que o trabalho não podia ser 
entendido apenas como atividade produtiva, mas também, como atividade estruturada dentro dos moldes capitalistas, sendo este o ponto de convergência de diferentes aspectos da alienação.

Marx (2004) redigiu críticas à economia política clássica, apresentando sua interpretação do conceito de alienação, ao mesmo tempo em que criticou a concepção hegeliana de alienação. Já na perspectiva de Mészáros (2006), Marx foi além, pois a concepção geral que Marx tinha da história e da alienação das relações sociais de produção, junto às suas análises das condições ontológicas objetivas de uma superação necessária da alienação e da reificação, acabaram por constituir um sistema de explicação da vida social, rigoroso e complexo.

Dentro desse sistema, ao escrever sobre a alienação, Marx conseguiu distinguir, cuidadosamente, a análise realizada por ele da crítica utópica elaborada pelos economistas clássicos. Essa distinção é fundamental, uma vez que o estudo da economia política pode proporcionar uma análise bem próxima da forma capitalista de atividade produtiva e consequentemente das reproduções relacionadas a essa atividade produtiva na sociedade. Na sua crítica à forma de análise dos economistas, Marx avançou cada vez mais em sua compreensão sobre a maneira como as relações econômicas e, principalmente o capital, reproduzem a sociedade.

O estudo sobre a economia política proporcionou a Marx uma análise da natureza e do funcionamento da atividade produtiva na sociedade capitalista, fazendo com que Marx se afastasse, cada vez mais, da alienação como foi constituída nos escritos anteriores, onde o trabalho aparecia como uma determinação que não estava relacionada à posição do indivíduo. Nesse contexto, passa a discutir-se não só o trabalho como atividade produtiva, mas também a forma como essa atividade produtiva se configura frente às necessidades e demandas da sociedade capitalista, e a maneira e condição na qual esse indivíduo está inserido nessa sociedade.

Para a economia política clássica, existia uma forma de atividade que seria bem diferente da atividade produtiva pensada por Marx, uma vez que estaria abstraída das determinações da sociedade, devido a generalização da condição de existência dos indivíduos envolvidos na atividade produtiva. Já na formulação marxista, essa atividade produtiva deixa de ser a-histórica e é determinada pelas relações econômico-sócio-políticas, passando a pensar uma relação constituída de trabalho, propriedade privada e divisão do trabalho, onde cada indivíduo assume um papel determinado dentro do sistema de produção, na qual o trabalho assume um papel de destaque devido as suas relações com o capital. Isso se evidencia quando Marx expressa:

Que a divisão do trabalho e a troca assentam-se sobre a propriedade privada não é outra coisa senão a afirmação de que o trabalho é a essência da propriedade privada, uma afirmação que o economista nacional não pode demonstrar, e que nós queremos demonstrar pra ele ( MARX, 2004, p. 155).

É importante apresentar que o economista clássico, não pensava o trabalhador como ser social, pelo contrário, sua análise tinha como base a divisão do trabalho e a acumulação do capital, deixando de lado o processo de mercantilização do homem, já que não considerava que o trabalho além de produzir 
mercadoria, também produzia uma enorme "desvalorização do mundo dos homens" (MARX, 2004, p. 81), pois transformava esse homem, também em uma mercadoria.

Marx (2004) entende o trabalho alienado como uma relação de estranhamento entre o homem e o sistema do dinheiro propriamente dito. Considerando a relação estranhamento - sistema do dinheiro, na análise de Mészáros (2006), o interesse da economia é o funcionamento do sistema, e para que a produção siga seu fluxo sem qualquer problema, a preocupação principal é garantir as condições básicas de subsistência do trabalhador:

Do ponto de vista da economia como uma ciência especial, o que importa, naturalmente, não é a avaliação das implicações humanas de um processo econômico objetivo, mas a análise das condições necessárias de funcionamento e reprodução sem perturbações do processo dado. É por isso que o economista político só está interessado nas condições do trabalhador na medida em que estas condições são necessárias à produção em geral, isto é, na medida em que são condições do trabalhador (MÉSZÁROS, 2006, p.136, destaque do autor).

O estudo da economia política não responde a todas as questões relacionadas à divisão do trabalho, à propriedade privada ou ao trabalho alienado propriamente dito, mas ajuda a compreender, a partir do fato econômico, a alienação do trabalho e o trabalho como atividade, passando a tratar a questão do trabalho alienado como um processo de estranhamento dentro da sociedade.

Ainda fazendo uma análise sobre a produção em geral e o estranhamento que se estabelece no sistema capitalista de produção, Marx (2004) levanta os seguintes questionamentos: "Se o produto do trabalho me é bizarro e se contrapõe a mim, como poder estranho, a quem pertencerá? Se a minha própria atividade não me diz respeito, se é uma atividade alheia, coagida, a quem pertencerá então?” (p. 118).

As questões apresentadas acima têm o intuito de trazer algumas das reflexões de Marx ao longo de sua trajetória, e também sobre como podemos pensar os desdobramentos do conceito de alienação neste caminho.

Como já foi dito anteriormente, é importante deixar claro que seria impossível trabalhar as inúmeras interpretações sobre o conceito de alienação, de uma forma sistemática. Entretanto, não se pode negar que, independente das muitas questões e abordagens existentes no campo do Marxismo, existiu uma revolução não só na trajetória intelectual de Marx, mas também em alguns de seus conceitos, como é o caso da alienação, que ganhou um desdobramento para a reflexão sobre a alienação do trabalho produtivo e do trabalhador nessa relação de produção, incluindo neste contexto a relação de estranhamento do indivíduo que exerce a função de produzir e reproduzir os valores próprios do capital.

Pensando a questão da alienação do trabalho produtivo e da forma como o trabalhador se percebe como indivíduo nessa relação de produção e reprodução de mercadorias e valores, pensamos em apresentar como esse conceito pode ser identificado no campo da educação, uma vez que esse campo tornou-se espaço em que são produzidos conhecimentos, mas também, disputas, interesses e produção e reprodução de valores e mercadorias, como a própria mão de obra. 


\section{Considerações sobre o processo de reprodução institucionalizada: o conceito de alienação no campo da educação}

Pensar a sociedade contemporânea exige que tal análise seja feita a partir das transformações constantes que a sociedade vem sofrendo e das necessidades e demandas que essa sociedade define para as instituições que fazem parte do seu sistema de produção e reprodução de valores, que, no caso deste artigo, são as instituições educacionais.

Considerando os fundamentos da análise aqui proposta, não se pode esquecer que os processos educacionais e os processos sociais mais abrangentes de reprodução da ordem do capital estão intimamente ligados. Então, com a preocupação voltada para essa relação profunda entre a sociedade e sua existência cotidiana nas instituições que a compõem, o conceito de alienação será trabalhado, a partir de agora, pensando e discutindo as questões voltadas para a educação e o processo educativo, principalmente no que diz respeito às suas instituições.

A educação, que pode ou poderia ser instrumento importante para uma mudança sócio-políticoeconômica, apresenta-se no sistema capitalista como um instrumento de apoio aos projetos da sociedade regida pelo capital, construindo um consenso que favorece a perpetuação do sistema dominante. Como afirma Mészáros (2005), nenhuma sociedade pode perdurar sem seu próprio sistema de educação, uma vez que as sociedades existem e desenvolvem-se por intermédio dos atos dos indivíduos que compõem as instituições.

Considerando que a sociedade capitalista organiza e estrutura seus sistemas sócio-políticoeconômicos e consequentemente suas instituições, segundo seus interesses, o sistema educacional é organizado, também seguindo algumas condições da sociedade, tais como, situação política e econômica dominante. Com isso, a sociedade capitalista, seguindo seus parâmetros de controle, não permite que a educação, e consequentemente, suas instituições, caminhem para além das necessidades do capital.

A educação é reprodutora do sistema, e dentro dos moldes de produção e reprodução da sociedade, a educação é fundamental para a reprodução da ideologia dominante, exercendo influência sobre os indivíduos durante todo o processo educativo, estabelecendo e restabelecendo ano após ano, o processo de alienação que perdurará até a inserção e permanência no mercado de trabalho e por toda a vida do indivíduo. Esse indivíduo passa toda sua vida internalizando valores mercantis impostos pela sociedade capitalista:

\footnotetext{
Quer os indivíduos participem ou não - por mais ou menos tempo, mas sempre em um número de anos bastante limitado - das instituições formais de educação, eles devem ser introduzidos a uma aceitação ativa (ou mais ou menos resignada) dos princípios reprodutivos orientadores dominantes da própria sociedade, adequando a sua posição na ordem social, e de acordo com as tarefas reprodutivas que lhes foram atribuídas. [...] ao internalizar as onipresentes pressões externas, eles devem adotar as perspectivas globais da sociedade mercantilizada como inquestionáveis limites individuais a suas aspirações pessoais (MÉSZÁROS, 2005, p. 44, 45).
}

Não se pode atribuir à educação a responsabilidade por todas as questões reprodutoras da sociedade, até porque, apesar das instituições formais de educação serem parte importante do sistema de internalização dos valores mercantis regidos pelo capital, ela é apenas uma parte desse grande sistema que 
é o sistema de produção de valores, apenas uma das muitas instituições que compõem o sistema capitalista. O indivíduo que faz parte desse enorme e complexo sistema está constantemente em contato com os mais diferentes tipos de instituição além da instituição escolar, como por exemplo, as instituições religiosas, familiares, as de cunho cultural, dentre outras.

Ainda de acordo com a análise de Mészáros (2005), a educação não é a força ideologicamente primária que consolida todo o sistema capitalista, nem tampouco é capaz de, por si só, fornecer uma explicação sistematizada ou fornecer uma alternativa para a situação imposta pelo poder do capital. O que é discutido aqui, é que, além da reprodução numa escala ampliada das atividades produtivas e dos valores mercantis, o sistema educacional da sociedade capitalista, também é responsável pela:

[...] produção e reprodução da estrutura de valores no interior da qual os indivíduos definem seus próprios objetivos e fins específicos. As relações sociais de produção reificadas sob o capitalismo não se perpetuam automaticamente. Elas só o fazem porque os indivíduos particulares interiorizam as pressões externas: eles adotam as perspectivas gerais da sociedade da mercadoria como os limites inquestionáveis de suas próprias aspirações. É com isso que os indivíduos contribuem para manter uma concepção do mundo e para a manutenção de uma forma específica de intercâmbio social, que corresponde àquela concepção de mundo (MÉSZÁROS, 2006, p. 263- 264).

Segundo Mészáros (2006), “a educação tem duas funções principais numa sociedade capitalista: (1) a produção das qualificações necessárias ao funcionamento da economia, e (2) a formação dos quadros e a elaboração dos métodos de controle político” (p.275), funções eminentemente de produção de conformidade e/ou consenso, que acontecem ou na dinâmica e no movimento da própria sociedade, ou através de seus poderes institucionalizados e legalmente estabelecidos.

Com isso, esperar que a educação faça com que a sociedade mercantilizada, que controla e organiza a própria educação segundo seus pressupostos, rompa com a lógica individualista e competitivista do capital, é um equívoco no contexto da análise marxista proposta neste artigo. O sistema de internalização dos valores da sociedade capitalista e da lógica autoritária do capital rege não só o sistema educacional, bem como todas as outras instituições sociais, além de fazer com que essas instituições sociais realizem suas tarefas, interiorizando as pressões e necessidades da sociedade.

No entanto, dentro de uma perspectiva onde a educação formal possui funções fundamentais para a manutenção do sistema capitalista, ela não poderia - devido ao limite de anos que o indivíduo permanece dentro dessa instituição e aos processos de exclusão social, próprios das sociedades capitalistas, que não garantem a todos os indivíduos o direito à escola - tratar das exigências e controles do capital sem a participação de outras instituições.

Nesse sentido, entendemos que os processos educativos, assim como suas instituições, bem como outras instituições que compõem o sistema capitalista, estão intimamente vinculados ao processo de alienação do indivíduo, até sua inserção no mundo do trabalho. A partir desses pontos de controle e manutenção do sistema, o domínio do capital acaba por assegurar que cada indivíduo adote, como sendo suas, as condições de reprodução, como interiorização de valores, funções e determinações.

Pensando a relação entre educação e trabalho, Gaudêncio Frigotto (1999) entende que, na lógica do capital humano, é necessário agregar fator humano ao estoque de capital e ao estoque de trabalho 
como fator de produtividade de modo a atingir o crescimento econômico. Nesse sentido, o capital humano significa, portanto, ganho de eficiência e aumento de capacidade de produzir.

No entanto, Frigotto (1999), apesar de realizar a análise sobre o capital humano, critica essa teoria, sugerindo seu caráter ideológico de classe, pois a negação das leis que regem a estrutura social capitalista, busca no individualismo a afirmação de sua ideologia, não cabendo uma discussão sobre as classes sociais que configuram o sistema capitalista de produção. Ainda segundo o autor:

[...] o raciocínio da concepção do capital humano, tanto do ponto de vista do desenvolvimento econômico como da renda individual, é que a educação, o treinamento são criadores de capacidade de trabalho. Um investimento marginal (pelo menos até certo nível) em educação ou treinamento permite uma produtividade marginal. Concebendo o salário ou a renda como preço do trabalho, o indivíduo, produzindo mais, conseqüentemente ganhará mais. A definição da renda, neste raciocínio, é uma decisão individual. Se passa fome, a decisão é dele (indivíduo); se fica rico, também." (FRIGOTTO, 1999, p. 50).

Com base na análise de Frigotto (1999), sobre o capital humano, que tem por objetivo a busca da eficiência e da produtividade, chegamos ao entendimento de como é perversa a lógica do sistema capitalista, uma vez que se utiliza do discurso você quer, você pode, você consegue, para manter essa produtividade. Sem se comprometer, ou comprometer suas exigências e consequências, a lógica perversa do capital faz com que o indivíduo assuma como suas, não só as aspirações, as metas do sistema econômico e seus sucessos individuais, mas também responsabiliza o indivíduo por seus fracassos no sistema social.

No que diz respeito à lógica capitalista, Mészáros (2004) entende que o capitalismo se apresenta como o sistema econômico mais desigual de toda a história, pois o autor afirma que o poder das instituições para sustentar a ideologia dominante, tem como objetivo controlar e manipular a ação, o pensamento, e o desejo dos indivíduos. Ainda para Mészáros (2004), esse controle e manipulação são chamados de "manipulação institucionalizada" (p. 104).

Para que essa manipulação seja aceita é necessário um sistema ideológico que proclame e inculque nos indivíduos, cotidianamente, valores que traduzam a falsa ideia de que todos são iguais diante da lei, além de estabelecer valores que configuram e reconfiguram os vínculos entre educação e trabalho.

Pensando os vínculos entre educação e trabalho que se estabelecem por toda a vida do indivíduo na sociedade capitalista, a educação acaba sendo mais uma mercadoria, em uma lógica em que tudo se vende e tudo se compra, e em uma prática em o que importa é o funcionamento das instituições, promovendo assim, a mercantilização da educação, onde até os espaços acabam funcionando com base no consumo e no lucro, tanto nas instituições públicas, como nas privadas.

No que diz respeito às instituições públicas e privadas, Gramsci (1989) afirma que a distinção pública e privada é uma distinção intrínseca ao direito burguês e válida onde o direito burguês exerce seu poder. Nesse sentido, o vínculo entre educação e trabalho é revelado, uma vez que a educação se concretiza de formas distintas, para diferentes tipos de indivíduos, ou seja, quem detém o poder econômico tem direitos diferentes daquele que não detém a riqueza. Dessa forma, o processo escolar garante diferentes formas de ingressar no mercado de trabalho. Essas diferentes formas de presença no 
mercado de trabalho são, exclusivamente, a venda e a compra da força de trabalho. Uma frase que traduz a ideia da dinâmica capitalista na relação educação/trabalho é: "diga-me onde está o trabalho em um tipo de sociedade e eu te direi onde está a educação" (MÉSZÁROS, 2005, p.17).

Podemos entender que a educação como processo de interiorização de valores não só para o mundo do trabalho, mas para a vida em sociedade, significa o processo de interiorização das condições de legitimidade do sistema que explora o trabalho e a vida do indivíduo como mercadoria. Com isso, através da aceitação das condições ditadas pelo capital e pela interiorização dos valores instituídos pela sociedade mercantilizada, podemos pensar também, mais uma forma em que a alienação pode se apresentar.

Pensando o conceito de alienação vinculado aos processos de mercantilização da vida do indivíduo que não se percebe como peça no mercado de compra e venda nas relações mercantilizadas pelo capitalismo, a questão da educação mercantil se sobressai, pois "a compreensão que o indivíduo passa a ter da sociedade é filtrada por meio dos óculos da 'educação mercantil'. Essa compreensão impede que o indivíduo perceba a relação indivíduo-sociedade como uma relação política e econômica" (SOUZA, 2005, p. 65).

$\mathrm{Na}$ ordem econômica, o indivíduo é tratado como uma mercadoria que possui os atributos e as possibilidades de quaisquer bens produzidos na sociedade. Souza (2005) afirma que essas dinâmicas de mercantilização da vida do indivíduo e de transmissão dos valores e padrões capitalistas afetam diretamente a educação, bem como se aproveitam dela.

Para Santos (2007) a ordem capitalista torna a prática educativa uma prática que ajuda a ampliar a desigualdade social, a preparar para o exercício de uma profissão, a educar para o consumo: "a educação feita mercadoria reproduz e amplia as desigualdades, sem extirpar as mazelas da ignorância. Educação apenas para a produção setorial, educação apenas profissional, educação apenas consumista, cria, afinal, gente deseducada para vida" (p. 154).

No que tange às interferências e influências que acontecem entre a sociedade e a educação, seria equivocado pensar em uma modificação ou organização interna das estruturas educacionais sem uma análise um pouco mais abrangente que reflita a sociedade capitalista como um todo, ou seja, suas relações sócio-político-econômicas. Uma reformulação significativa da educação seria praticamente inviável, sem uma correspondente transformação do quadro social no qual as práticas educativas devem cumprir suas funções. Segundo Mészáros (2005), ao parafrasear José Martí, "as soluções não podem ser apenas formais; elas devem ser essenciais" (p.35):

A educação institucionalizada, especialmente nos últimos 150 anos, serviu - no seu todo- ao propósito de não só fornecer os conhecimentos e o pessoal necessário à máquina produtiva em expansão do sistema do capital, como também gerar e transmitir um quadro de valores que legitima os interesses dominantes, como se não pudesse haver nenhuma alternativa à gestão da sociedade, seja na forma "internalizada" (isto é, pelos indivíduos devidamente "educados" e aceitos) ou através de uma dominação estrutural e uma submissão hierárquica e implacavelmente imposta (MÉSZAROS, 2005, p.35).

Pensar soluções quando se problematiza a questão da produção e da reprodução da sociedade pelas instituições educacionais nos leva a refletir sobre as regras de comportamento impostas pelo 
capitalismo, pois dentro de um consenso alienante de formulações, a educação reproduz as atividades produtivas que cercam o complexo sistema educacional da sociedade, que além dessas formulações e reformulações, produz e reproduz valores através dos quais os indivíduos definem seus próprios objetivos, ainda dentro de um quadro alienante de formulações.

\section{Referências}

FEUERBACH, L. A essência do Cristianismo. Porto: Fundação Calouste Gulbenkain, 2 ed., 2002.

FORNES, R. C. A alienação do trabalho na Pós-modernidade. Dissertação de mestrado defendida e aprovada em novembro de 2008, no Programa de Pós-Graduação em Serviços Sociais da Universidade do Estado do Rio de Janeiro. Rio de Janeiro: UERJ, 2008.

FRIGOTTTO, G. A produtividade da escola improdutiva: um (re) exame das relações entre educação e estrutura econômico-social e capitalista. São Paulo: Cortez, 1999.

GRAMSCI, A. Os intelectuais e a organização da cultura. Rio de Janeiro: Civilização Brasileira, 1989.

HANDFAS, A. Uma leitura crítica das pesquisas sobre as mudanças nas condições capitalistas de produção e a educação do trabalho. Tese de doutorado defendida e aprovada em setembro de 2006, na Faculdade de Educação da Universidade Federal Fluminense. Rio de Janeiro: UFF/ RJ, 2006.

HEGEL, G.W. F. Filosofia da História. Brasília: UNB, 1999.

KONDER, L. Marxismo e alienação. Rio de Janeiro: Civilização Brasileira, 1965.

MARX, K e ENGELS, F. La Ideologia Alemana. Tradução de Wenceslao Roces. Havana: Edicion Revolucionaria, 1966.

MARX, K. Manuscritos Econômico-filosóficos. Tradução de Alex Marins. São Paulo: Martin Claret, 2004 (A obra-prima de cada autor).

MÉSZÁROS, I. A educação para além do capital. Tradução de Isa Tavares - São Paulo: Boitempo, 2005.

MÉSZÁROS, I. A teoria da alienação em Marx. Tradução Isa Tavares - São Paulo: Boitempo, 2006.

MÉSZÁROS, I. O poder da ideologia. São Paulo: Boitempo, 2004.

SANTOS, M. O espaço do cidadão. 7 ed. São Paulo: Editora Edusp, 2007.

SOUZA, S. C. Educação: mercadoria ou projeto civilizatório? Rio de Janeiro: Maanaim, 2005.

\footnotetext{
Notas:

1 Professora Adjunta do Instituto Multidisciplinar da Universidade Federal Rural do Rio de Janeiro (UFRRJ), Departamento de Educação e Sociedade IM/UFRRJ. Líder do Grupo de Estudos e Pesquisas em Ensino Superior e Pesquisa em Educação - ESPE/UFRRJ. Orcid: https://orcid.org/0000-0001-6186-605X Email: licacmoura@hotmail.com
} 